\title{
Classical-classical transfer: Excitatory associations between "competing" motivational stimuli during classical conditioning of the rabbit
}

\author{
ROBERT W. TAIT, LIONEL J. QUESNEL, and WILLIAM N. TEN HAVE \\ University of Manitoba, Winnipeg, Manitoba, Canada
}

\begin{abstract}
A sensory preconditioning analogue was employed to separate signaling effects from motivational effects observed in appetitive-to-aversive transfer of training. Rabbits received appetitive conditioning (tone-water pairings) of the jaw-movement response, followed by aversive conditioning of the nictitating membrane response, during which water delivery served as the CS for paraorbital shock. When the tone was subsequently presented, only subjects exposed to both sets of pairings demonstrated conditioned jaw movement and nictitating membrane responses. The occurrence of both responses to the tone is inconsistent with the action of reciprocal inhibition between motivational states. The results are interpreted in terms of multiple mediators for transferof-training paradigms.
\end{abstract}

Many influential theories of instrumental behavior assume that there exist aversive and appetitive motivational states in the central nervous system which act reciprocally to inhibit one another (e.g., Konorski, 1967; Rescorla \& Solomon, 1967). Each motivational state is thought to be activated directly by an unconditioned stimulus (US) or indirectly by a conditioned stimulus (CS) that has been paired with the US. The most conclusive evidence for competing motivational states (see Dickinson \& Pearce, 1977) comes from classical-classical transfer paradigms in which a CS is initially paired with a US from one motivational state and subsequently paired with a US from the other motivational state (Bromage \& Scavio, 1978; Krank, 1985; Scavio, 1974, 1975; Scavio \& Gormezano, 1980). For example, Scavio $(1974,1975)$ has shown that conditioning the rabbit's nictitating membrane response to a tone CS by pairing the CS with a shock US will retard the development of a jaw-movement response to that CS when it is subsequently paired with an oral injection of a water US. Since Scavio also showed that nictitating membrane and jaw-movement conditioned responses (CRs) were statistically independent, the retarded acquisition of the jaw-movement conditioned response could not be attributed to peripheral incompatibility of responses. Hence, Scavio's results support a theory in which central motivational states inhibit one another.

In contrast, when USs from opposing motivational states are directly paired with one another, conditioning appears to occur rapidly (Asratyan, 1965, 1980; Beritoff, 1965; Dearing \& Dickinson, 1979; Gormezano \& Tait, 1976;

This research was supported by Grant A0312 from the Natural Sciences and Engineering Research Council of Canada to R. W. Tait. Requests for reprints should be addressed to R. W. Tait, Psychology Department, University of Manitoba, Winnipeg, Manitoba, Canada R3T 2N2.
Tait, 1974). For example, Tait (1974) showed that when a water US is followed by a paraorbital shock US, the water becomes an effective CS for the aversively motivated nictitating membrane response. When the temporal order of the stimuli was reversed in a separate group of rabbits, forward conditioning of the appetitively motivated jaw-movement response to the shock occurred. The occurrence of forward conditioning under both temporal orders of the USs is problematic for theories that assume competing motivational states. According to these theories, the USs should reciprocally inhibit one another and only the more motivationally intense stimulus should support conditioning. Thus, at least one of the temporal orders should have failed to produce conditioning.

There are three possible accounts for the discrepant interpretations arising from the comparison of results obtained with the classical-classical transfer and US-US pairing procedures. First, the motivational effects of CSs and USs could differ. It is possible that activation of reciprocal inhibition between motivational states is triggered primarily by CSs and only minimally by USs. Second, the classical-classical transfer paradigm is sequentially organized, with first one motivational state activated and conditioned and then the other. On the other hand, USUS pairings activate both motivational systems in immediate succession. Hence, reciprocal inhibition could be observed primarily with separate phase sequential applications of stimuli, but not with near-simultaneous applications. And third, when two USs are temporally paired, the first US becomes a direct cue for the second US. Thus, the cuing consequence of US-US pairings could be a more powerful regulator of performance than the motivational consequence.

The present experiment was designed to bridge the procedural differences between the classical-classical 
transfer and US-US pairings paradigms. A three-stage experiment was conducted that was analogous to sensory preconditioning procedures. In the first phase, a tone CS signaled the delivery of water into a rabbit's oral cavity and the jaw-movement response was conditioned. In the second phase, water injections were used as CSs for paraorbital shock and the nictitating membrane response was conditioned. In the third phase, the tone was presented by itself. If the observation of acquired motivational properties of a CS result from either unique attributes of conditioned motivational states or the phasing of motivational activation and conditioning, then the third-phase tone presentations should not evoke the nictitating membrane responses. On the other hand, if the acquired cuing properties of a CS are stronger than its acquired motivational properties, then the associative characteristics of the sensory preconditioning paradigm should be observed. In sensory preconditioning, the initial CS subsequently produces the response that is conditioned in the second phase (Brogden, 1939; Suboski \& Tait, 1972). Thus, the expected associative outcome would be the observation of nictitating membrane responses to the tone during the third phase as a result of the associative network established by first pairing the tone with water and then pairing the water with shock.

\section{METHOD}

\section{Subjects}

The subjects were 32 male and female New Zealand albino rabbits (Oryctolagus cuniculus), approximately 100 days of age and weighing between 2.5 and $3.0 \mathrm{~kg}$. The rabbits were obtained from the Kleefeld Rabbitry of Tourond, Manitoba.

\section{Apparatus}

The conditioning apparatus and methods for transduction of jawmovement (JM) and nictitating membrane (NM) responses have been described in detail elsewhere (Gormezano, 1966; Smith, Di Lollo, \& Gormezano, 1966). In the present study, both the programming of stimuli and analyses of responses were controlled by a software system (modified from Tait \& Gormezano, 1974) implemented on a Raytheon 703 computer.

Briefly, the eight experimental chambers were the drawers of two legal-size, fireproof, file cabinets, which were vented continuously by running fans and illuminated by two $24-\mathrm{V}, 6-\mathrm{W}$ incandescent bulbs. The subjects were firmly restrained in boxes by the use of Plexiglas backplates, head yokes, and foam-covered pinnae clamps. For JM transduction, a counterbalanced rod, mechanically coupled to the stem of a rotary potentiometer, was inserted through a stainless steel Autoclip affixed to the lower mandible of the subject's jaw. Jaw movements caused a change of voltage in the potentiometer that was sensed by an analog-to-digital (A/D) input channel of the Raytheon 703 computer. The criterion for a JM CR was an A/D change corresponding to any $1-\mathrm{mm}$ movement of the jaw that occurred during the CS-US interval. The CS for JM conditioning was a $500-\mathrm{msec}, 1000-\mathrm{Hz}, 80-\mathrm{dB}$ tone. The US was a $500-\mathrm{msec}$, 1-ml injection of water, delivered from a holding tank, pressurized at $20 \mathrm{lb}$, via a system of Tygon tubing. The end of the tubing was coupled by a Luer-Lock to a 16-ga needle, which was slip-fitted into a fistula implanted in the animal's right cheek.

To transduce the NM response, an L-shaped counterbalanced piano wire was affixed to the axle of a potentiometer and coupled to a nylon loop sutured into the animal's nictitating membrane with a length of silk thread. Movements of the nictitating membrane pulled the piano wire and rotated the potentiometer's axle. Again, voltage changes in the potentiometer were conducted to an $A / D$ input channel of the computer, and the criterion for a $C R$ corresponded to a 1-mm extension of the NM during the CS-US inter$\mathrm{val}$. The CS for NM conditioning was a 500-msec, 1-ml oral injection of water delivered into the subject's right cheek. The US was a 50-msec, $2.5-\mathrm{mA}, 60-\mathrm{Hz}$ paraorbital shock delivered through alligator clips attached to two stainless steel Autoclip sutures positioned $10-\mathrm{mm}$ caudal to and $10-\mathrm{mm}$ above and below the horizontal plane of the rabbit's right eye. For the conditioning procedures of both the JM and NM responses, the CS-US interval was $500 \mathrm{msec}$, and for all phases of the experiment, the mean intertrial interval was $120 \mathrm{sec}$.

\section{Procedure}

Two days after their arrival, the animals were placed in a restraining box, the areas around the right eye and right cheek were depilated, and two Autoclip sutures were implanted behind the right eye. A length of 00 Ethicon monofilament nylon was sutured into the membrane and tied to form a 2-mm loop. On the next day, the subjects were anesthetized with an intraperitoneal injection of approximately $2.0 \mathrm{ml}$ of sodium pentobarbital $(50 \mathrm{mg} / \mathrm{ml})$. A small fistula was then implanted in the right cheek in the following manner: the cheek was disinfected with isopropyl alcohol and a small hole was made in the cheek with a leather punch; a cannula constructed from a $2.5-\mathrm{cm}$ length of PE-240 polyethylene tubing, heat flared against a plastic washer, was inserted into the oral cavity and pulled through the hole in the cheek; and finally, a plastic washer was placed over the protruding end of the tubing, which was subsequently heat flared against the washer. The rabbits were then returned to their home cages where food and water were available ad lib. On the 2 nd postoperative day, a water maintenance regime of $60 \mathrm{ml}$ per day was implemented and maintained for the duration of the experiment. On the 6th postoperative day, the subjects were assigned randomly to one of four groups $(n=8)$, fitted with potentiometers, and placed in a conditioning chamber for an adaptation session. The adaptation session was equal to the subsequent conditioning sessions in length, but no stimuli were administered.

On the next day, the three-phase experimental protocol commenced. The phases were: appetitive conditioning of the JM response to the tone; aversive conditioning of the NM response, with the water US of the first phase serving as the CS; and a transfer of control test to the tone.

Group identification was accomplished with a two-letter code that indicated the receipt of paired trials (P), unpaired trials (U), or no trials (N) in Phases 1 and 2, respectively. In Phase 1, Groups PP and $P N$ received 25 tone-water pairings for 10 consecutive days. Subjects in Group UP received unpaired presentations of tone and water for 10 consecutive days. On each day, the subjects in Group UP received $25 \mathrm{CS}$ and $25 \mathrm{US}$ presentations according to a Gellerman series with a minimum separation of $50 \mathrm{sec}$. Subjects in Group NP were placed in the conditioning chambers for time periods equivalent to the session length of the other groups, but received no stimuli. JM responses were monitored in Group UP on CS trials and in Group NP in the intervals that corresponded to the 500-msec CS delivery of Groups PP and PN.

Phase 2 commenced on the day following Phase 1. During Phase 2, Groups PP, UP, and NP received 25 water-paraorbital shock pairings each day for 7 consecutive days. Subjects in Group PN were placed in the conditioning chambers daily for time periods equivalent to the experimental sessions for the other groups, but no stimuli were presented. Nictitating membrane movements that occurred during intervals that corresponded to CS administration in the other groups were recorded.

On the day following the last Phase 2 session, the Phase 3 transferof-control test was implemented. In Phase 3, subjects of all groups 
received one session of 25 tone-alone presentations. The occurrence of JM and NM CRs in the interval between CS onset and offset were recorded.

\section{RESULTS}

\section{Phase 1: Tone-Water Pairings}

Over the 10 days of JM acquisition, the mean percentages of CRs for Groups PP, PN, UP, and NP were 64.8, $50.2,31.5$, and 5.8, respectively. Duncan's multiple range test $(\alpha=0.05)$ applied to the significant group effect $[F(3,28)=14.02, p<.01]$ that was observed in a repeated measures ANOVA showed that Groups PP and PN did not differ from one another. Moreover, both groups had a higher percentage of CRs than Group UP, which had, in turn, a significantly higher percentage of CRs than Group NP.

The left-hand frame of Figure 1 depicts the mean percentage of JM CRs on each of the 10 days of tone-water pairings for Groups PP, PN, UP, and NP. The figure shows that groups PP and PN had similar gradual acquisition functions, whereas Group NP had a marginal increase in the percentage of CRs. In addition, Group UP had intermediate levels of acquisition, which is characteristic of the pseudoconditioning that occurs with the JM response (Sheafor, 1975). The ANOVA substantiated the graphical interpretation by identifying a significant group $\times$ days effect $[F(27,252)=2.76, p<.01]$.

During Phase 1 , the mean percentages of NM responding to the tone were $7.9,8.6,5.4$, and 2.8 for Groups PP, PN, UP, and NP, respectively. An ANOVA indicated that group differences were not reliable $[F(3,28)=2.21]$.
There was, however, a small, but significant, increase in the percentage of NM responses over the 10 days (from $1.7 \%$ on Day 1 to $6.7 \%$ on Day 10$)$ of Phase $1[F(9,252)$ $=3.32, p<.01]$.

\section{Phase 2: Water-Shock Pairings}

Over the 7 days of NM acquisition, the mean percentages of CRs to the water CS for Groups PP, PN, UP, and NP were $64.0,2.7,86.0$, and 80.0 , respectively. Duncan's multiple range test, applied to the significant group effect $[F(3,28)=107.77, p<.01]$ in a repeated measures ANOVA, indicated that Groups UP and NP did not differ and that both had significantly higher percentages of CRs than did Group PP, which had a reliably higher percentage of CRs than Group PN.

The right-hand frame of Figure 1 presents the mean percentage of NM CRs to the water CS on each of the 7 days of water-shock pairings for Groups PP, PN, UP, and NP. The figure shows that Groups UP and NP acquired the NM CR very rapidly and to high asymptotic values. On the other hand, Group PP appeared to have a retarded acquisition and Group PN demonstrated negligible responding. The ANOVA confirmed the graphical interpretation by yielding a significant groups $\times$ days effect $[F(18,168)$ $=11.11, p<.01]$.

During Phase 2, there was a high elicitation rate of JM unconditioned responses (URs) by the water US (mean percentages of JM URs were $97.9,97.7$, and 96.8 for Groups PP, UP, and NP, respectively). An ANOVA revealed that percentage of JM URs failed to differ between groups $[F(2,21)<1.0]$ or over the 7 days of Phase 2 $[F(6,126)=1.35]$.
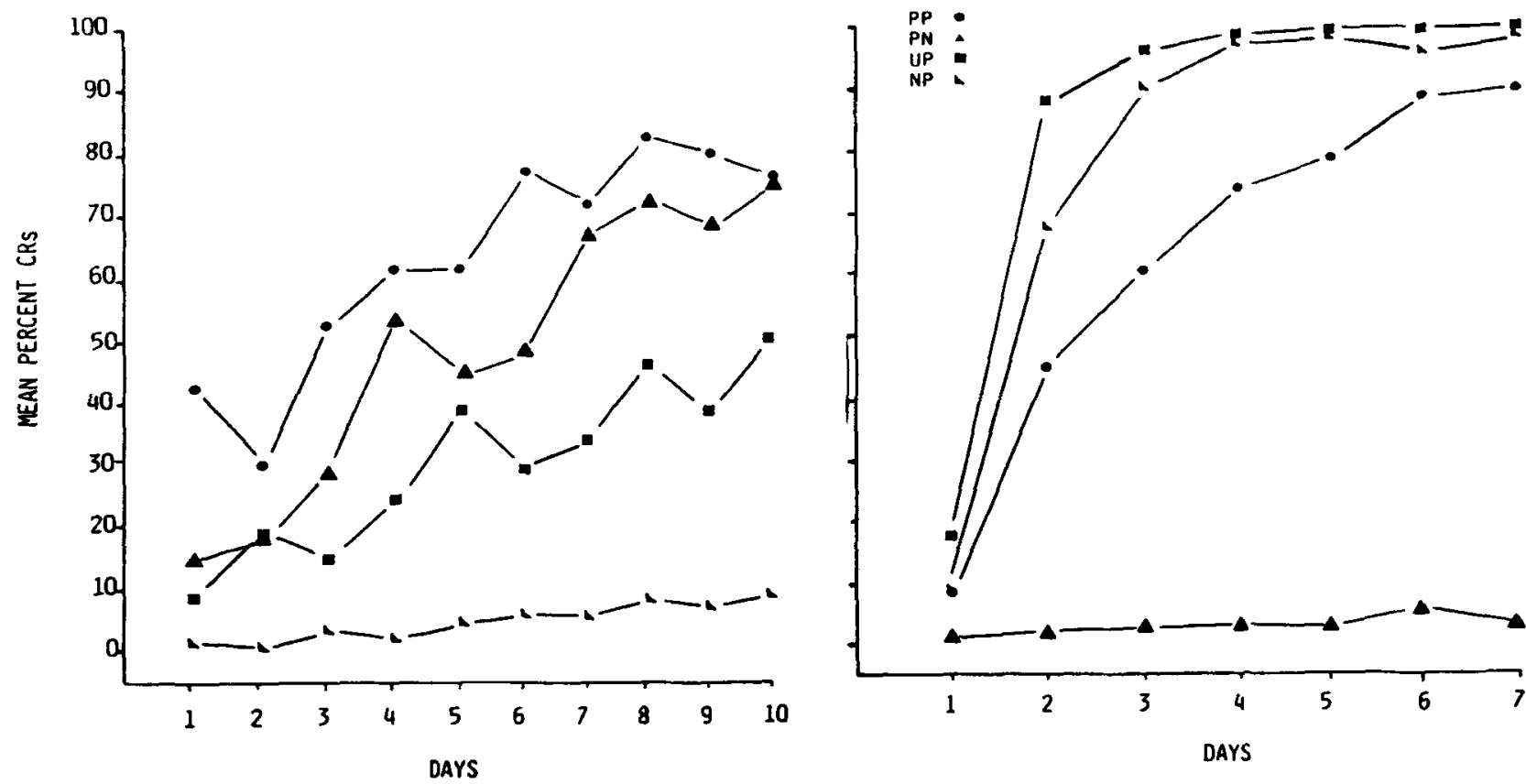

Figure 1. The left-hand frame depicts the mean percentages of JM CRs for Groups PP, PN, UP, and NP as a function of the 10 days of Phase 1 acquisition. The right-hand frame illustrates the mean percentages of NM CRs for Groups PP, PN, UP, and NP as a function of the 7 days of Phase 2 acquisition. 


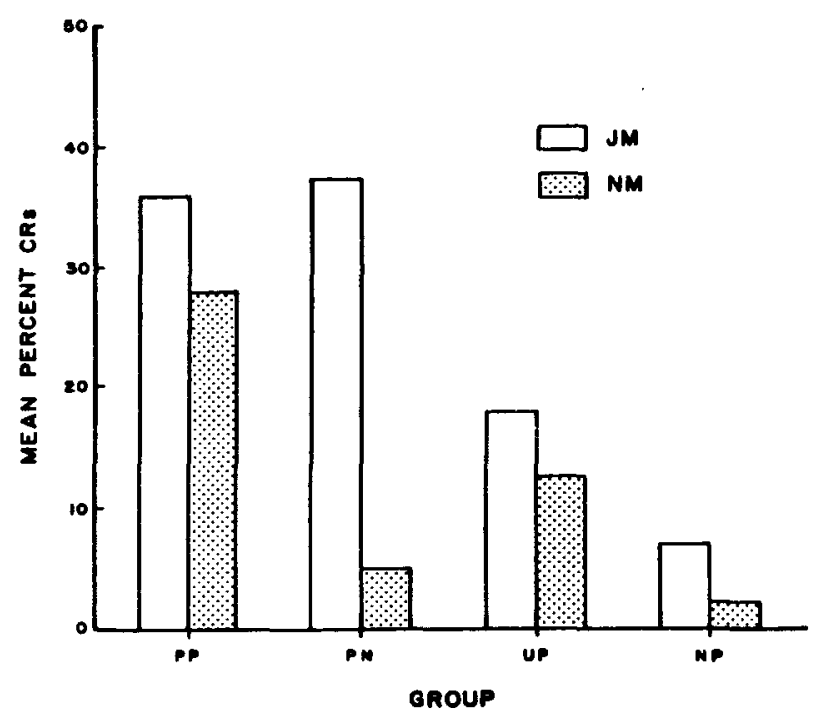

Figure 2. The mean percentages of JM and NM CRs for Groups PP, PN, UP, and NP during tone-alone presentations in Phase 3.

Phase 3: Tone-Alone Presentations

Figure 2 illustrates the mean percentages of $\mathrm{JM}$ and $\mathrm{NM}$ CRs for Groups PP, PN, UP, and NP during the Phase 3 tone-alone presentations. For the JM CRs, the highest levels of responding occurred in Groups PP and PN, and the lowest occurred in Group NP; Group UP was midway between the extremes. An ANOVA yielded a significant group effect $[F(3,28)=12.39, p<.01]$, and Duncan's multiple range test confirmed the rank ordering of the groups.

For NM CRs, Figure 2 suggests that the percentage of NM CRs was much higher for Group PP than for the other three groups. The statistically significant group effect $[F(3,28)=5.86, p<.05]$ resulted from the higher responding in Group PP relative to the other three groups, which did not differ from one another, according to Duncan's multiple range test. Since nonassociative interpretations for the NM CRs observed in Group PP can be ruled out because the NM response is not sensitive to pseudoconditioning or sensitization effects (Gormezano, 1972), the NM CRs must be a result of an associative chain established in Phases 1 and 2.

To determine whether the JM and NM responses to the tone in Group PP were independent, the percentages of NM CRs, percentages of JM CRs, and percentages of trials on which both NM and JM CRs occurred were tabulated. A chi-square test was applied to the percentages of joint occurrence of the two responses versus the product of the individual percentage of CRs for each response system (see Scavio, 1974). The nonsignificant chi-square $\left(\chi^{2}=1.59, N=7\right)$ indicated that the occurrence of JM and NM CRs to the tone was statistically independent, and replicated the prior results of Scavio (1974) and Krank (1985).

\section{DISCUSSION}

The acquisition of responding in Phase 2 for Groups PP, UP, and NP replicated the observations of Tait (1974) with water-shock pairings. Group PP, however, demonstrated slower acquisition than Groups NP and UP. Since Groups PP and UP received the same number of water presentations in Phase 1, differences between the groups are unlikely to have arisen from nonassociative effects produced by water delivery. Hence, the retarded acquisition of Group PP in Phase 2 reflects the history of pairings received in Phase 1.

It is not clear how having served as a US in Phase 1 could influence the ability of water to serve as a CS in Phase 2. It is possible that in Phase 1, independent forward and backward associations were established between representations of the tone CS and water US (Asratyan, 1965, 1980; Gormezano \& Tait, 1976; Wagner, 1981). Since backward associations in classical conditioning appear to be inhibitory (Hall, 1984), the retarded Phase 2 acquisition would reflect the inhibitory backward watertone association's interfering with the establishment of the excitatory forward water-shock association. Alternatively, the Phase 1 tone-water pairing could have activated a reciprocal inhibitory link into the aversive motivational structure from the appetitive motivational structure. During Phase 2, the inhibitory link could interfere with the ability of the water to serve as a CS by diminishing the effectiveness of the shock US. This interpretation rests on the validity of three related assumptions. First, US presentations, such as the water-alone trials in Group UP, would not be able to activate a reciprocal inhibitory link between motivational states. The absence of Phase 2 differences between Groups UP and NP is consistent with this assumption. Second, the activation of a reciprocal inhibition link between motivational states would have to be a consequence of conditioning to neutral CSs. And third, once enabled, the link could be triggered by either the CS or the US. The Phase 2 retarded acquisition of Group PP relative to Group UP is consistent with the latter two assumptions. Thus, either the acquired cuing or the acquired motivational interpretation could account for the Phase 2 acquisition effects.

In Phase 3, Group PP exhibited the same level of conditioned jaw-movement responses as Group PN. The absence of differences in appetitive responding indicated that the Phase 2 water-shock pairings did not influence either the retention or the production of appetitive responses to the tone. In addition, during Phase 2, the elicitation of JM URs by the water was very high and did not change as a consequence of pairing with shock. Thus, the aversive motivational state appeared to have negligible effects on the representation of an appetitive US or the subsequent activation of this representation by a CS.

In Phase 3, more NM CRs occurred to the tone in Group PP than in the other three groups. Since Group PP was the only group that received both tone-water and 
water-shock pairings, it would appear that the associations formed during each phase became linked in an associative network during the successive phases. Therefore, Group PP demonstrated an effect that is analogous to sensory preconditioning. The analogy is made stronger by the observation that the occurrences of the JM and NM CRs of Group PP were statistically independent during Phase 3. Statistical independence of response occurrences has been used to argue against peripheral response competition interpretations of mediated behavior (Scavio, 1974). An extension of Scavio's argument leads to the conclusion that if the responses are independent, then neither competition between the responses being measured nor the chaining of the measured responses can operate to mediate behavior. Thus, the statistical independence of the NM and JM responses indicated that peripheral theories of the associative network observed with Group PP are less tenable than central theories, an interpretation that parallels the interpretation of sensory preconditioning results (Cousins, Zamble, Tait, \& Suboski, 1971).

Accordingly, the present experiment indicated that the associations between the central representations of tone and water formed in Phase 1 were linked to the associations between the central representations of the water and shock that were established in Phase 2. As a consequence, when the tone was delivered in Phase 3, the central representation of the water was activated, yielding the JM response, and the activated representation of the water excited the central representation of the shock, which produced the NM response. To produce both responses to the tone, both associations would have to be excitatory. Therefore, the observation of NM responses to the tone is inconsistent with the action of reciprocal inhibition between motivational states.

The failure to find evidence for reciprocal inhibition is consistent with the observations from the US-US pairing procedure (Asratyan, 1965, 1980; Beritoff, 1965; Gormezano \& Tait, 1976; Tait, 1974), in which one US serves as the cue for a second. The present results extend previous observations by showing that the cue function of the initial US can be chained to a CS by the sequential application of separate pairing operations.

For excitatory associations to develop in the US-US pairing procedure, either the USs must not activate motivational systems that reciprocally inhibit one another or the cuing function of the temporally first US dominates its motivational function. The first alternative is an unlikely possibility for at least two reasons. First, Scavio (1974, 1975; Bromage \& Scavio, 1978; Scavio \& Gormezano, 1980) and others (e.g., Krank, 1985), monitoring similar response systems and employing similar conditioning parameters with the rabbit, have demonstrated acquired motivational effects to CSs that are consistent with competing motivational states theories. It is unlikely that a CS would have motivational consequences after pairings with a US if the US also did not produce similar motivational effects. And second, when shock and water are paired, the shock becomes a less effective punisher (Dearing \& Dickinson, 1979). Accordingly, US-US pairings may produce motivational consequences, but these consequences may be secondary and identified primarily through subsequent indirect tests (e.g., classical-classical and classical-instrumental transfer procedures).

Accordingly, it is more likely that classical conditioning may result in two independent associative effects, one reflecting a cuing function and the other illustrating a motivational consequence. Although independent cuing and motivational effects have been assigned to classically conditioned CSs in mediational theories of instrumental behavior (e.g., Konorski, 1967; Overmier \& Lawry, 1979; Spence, 1956), systematic examination of the control of the consequences of classical conditioning has not followed (Bromage \& Scavio, 1978). As Soltysik (1971) has asserted, the two consequences of classical conditioning could be differentially sensitive to parametric variables employed in classical conditioning and therefore be differentially observed. Recent results by Tait and Saladin (1986) support Soltysik's (1971) assertion of differential parametric sensitivity of the two associative processes by showing that backward pairings of paraorbital shock and tone produced inhibitory backward conditioning of the nictitating membrane response (the associative cuing consequence), but excitatory backward conditioning when the CS was used as a conditioned punisher of licking in the same rabbit (the associative motivational consequence). The simultaneous occurrence of excitatory and inhibitory associative consequences of a common treatment suggests that the cuing and motivational associative effects are differentially sensitive to the backward conditioning procedures employed and may be independent of one another.

The present results further suggest that the cuing function of conditioning dominates or masks the motivational function when both are available to mediate acquisition. Such an observation is consistent with results reported by Overmier and Lawry (1979) for instrumental-instrumental transfer-of-training paradigms in which the response cuing or signaling properties acquired by a stimulus were more potent mediators than the acquired motivational properties. Like the instrumental-instrumental transferof-training paradigm, the classical-classical transfer-oftraining paradigm appears to identify motivational interactions only when cuing mediators are not active (e.g., Scavio, 1974, 1975).

\section{REFERENCES}

AsRatyan, E. A. (1965). Compensatory adaptations, reflex activity, and the brain.. Oxford: Pergamon Press.

AsRatyan, E. A. (1980). Reflex mechanisms of motivational behavior. In R. F. Thompson, L. H. Hicks, \& V. B. Shvyrkov (Eds.), Neural mechanisms of goal-directed behavior and learning. New York: Academic Press.

BERITOFF, J. S. (1965). Neural mechanisms of higher vertebrate behavior. Boston: Little, Brown.

Brogden, W. J. (1939). Sensory pre-conditioning. Journal of Experimental Psychology, 25, 323-332. 
Bromage, B. K., \& Scavio, M. J. (1978). Effects of an aversive CS+ and $C S$ - under deprivation upon successive classical appetitive and aversive conditioning. Animal Learning \& Behavior, 6, 57-65.

Cousins, L. S., Zamble, E., TaIT, R. W., Suboski, M. D. (1971). Sensory preconditioning in curarized rats. Journal of Comparative \& Physiological Psychology, 77, 152-154.

Dearing, M. F., \& Dickinson, A. (1979). Counterconditioning of shock by a water reinforcer in rabbits. Animal Learning \& Behavior, 7, 360-366.

Dickinson, A., \& Pearce, J. M. (1977). Inhibitory interactions between appetitive and aversive stimuli. Psychological Bulletin, 84, 690-711.

Gormezano, I. (1966). Classical conditioning. In J. B. Sidowski (Ed.), Experimental methods and instrumentation in psychology. New York: McGraw-Hill.

GoRmEZANO, I. (1972). Investigations of defense and reward conditioning in the rabbit. In A. H. Black \& W. F. Prokasy (Eds.), Classical conditioning II: Current theory and research. New York: Appleton-Century-Crofts.

Gormezano, 1, \& TaIt, R. W. (1976). The Pavlovian analysis of instrumental conditioning. Pavlovian Journal of Biological Science, 11, 37-55.

HaLL, J. F. (1984). Backward conditioning in Pavlovian type studies: Reevaluation and present status. Pavlovian Journal of Biological Science, 19, 163-168.

KONORSKI, J. (1967). Integrative activity of the brain: An interdisciplinary approach. Chicago: Univeristy of Chicago Press.

Krank, M. D. (1985). Asymmetrical effects of Pavlovian excitatory and inhibitory aversive conditioning on Pavlovian appetitive responding and acquisition. Learning \& Motivation, 16, 35-62.

Overmier, J. B., \& LaWry, J. A. (1979). Pavlovian conditioning and the mediation of behavior. In G. H. Bower (Ed.), The psychology of learning and motivation. New York: Academic Press.

Rescorla, R. A., \& Solomon, R. L. (1967). Two-process learning theory: Relationships between Pavlovian conditioning and instrumental learning. Psychological Review, 74, 151-182.

ScAvio, M. J. (1974). Classical-classical transfer: Effects of prior aversive conditioning upon appetitive conditioning in rabbits. Journal of Comparative \& Physiological Psychology, 86, 107-115.
SCAvio, M. J. (1975). Classical-classical transfer: CR interactions involving appetitive and aversive CSs and USs. Bulletin of the Psychonomic Society, 6, 475-477.

Scavio, M. J., \& Gormezano, I. (1980). Classical-classical transfer. Effects of prior appetitive conditioning upon aversive conditioning in rabbits. Animal Learning \& Behavior, 8, 218-224.

SHEAFOR, P. J. (1975). "Pseudoconditioned"' jaw movements of the rabbit reflect associations conditioned to contextual background cues. Journal of Experimental Psychology: Animal Behavior Processes, 1 , 245-260.

Smith, M. C., Di Lollo, V., \& Gormezano, I. (1966). Conditioned jaw movement in the rabbit. Journal of Comparative \& Physiological Psychology, 62, 479-483.

SolTySIK, S. (1971). On the homogeneous and heterogeneous transformation of conditioned reflexes: A comment on the Overmier and Payne case of positive transfer. Acta Neurobiologiae Experimentalis, 31, 401-407.

SPENCE, K. W. (1956). Behavior theory and conditioning. New Haven: Yale University Press.

Suboski, M. D., \& TAIT, R. W. (1972). The logic of sensory preconditioning theory and research. Proceedings of the Annual Convention of the American Psychological Assocation, 7(Pt. 2), 783-784.

TAIT, R. W. (1974). Assessment of the bidirectional conditioning hypothesis through the UCS $-U C S_{2}$ conditioning paradigm. Unpublished doctoral dissertation, University of Iowa.

TAIT, R. W., \& GoRmeZano, I. (1974). A minicomputer program for stimulus control and analog data for discrete trial paradigms in biological preparations: Classical conditioning. Behavior Research Methods \& Instrumentation, 6, 295-300.

TAIT, R. W., \& Saladin, M. E. (1986). Concurrent development of excitatory and inhibitory associations during backward conditioning. Animal Learning \& Behavior, 14, 133-137.

WAGNER, A. R. (1981). SOP: A model of automatic memory processing in animal behavior. In N. E. Spear \& R. R. Miller (Eds.), Information processing in animals: Memory mechanisms. Hillsdale, $\mathrm{NJ}$ : Erlbaum.

(Manuscript received September 26, 1985; revision accepted for publication March 3, 1986.) 